\title{
Lack of transformation in sport and the long-term athlete development programme
}

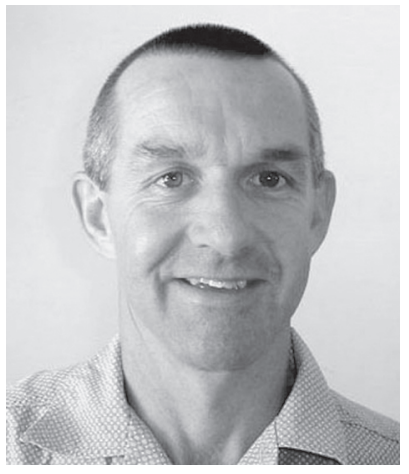

Statements are often made about 'identifying talent' as a means of addressing the imbalances in the demographics of the players in the top representative teams. Politicians in particular make innuendos about coaches and administrators being selectively biased in their choice of certain players, at the exclusion of other players, hence slowing down transformation.

However, what they fail to consider when making these statements is that a coach depends on a winning team for the longevity of his job. Therefore it is disingenuous to think that a coach will place his or her job in jeopardy by not selecting the best players who can contribute to a winning team. Attributing the lack of transformation to the coaches and administrators is simply a cunning way of taking the focus off the real source of the problem. The real source of the problem has a wider context than merely being the bias of coaches and administrators. The real source of the problem can be attributed directly to the inequities that exist from childhood in different regions of the country.

Preparation begins at preschool, where the child should have access to healthy adequate nutrition and an opportunity to develop fundamental motor skills. If these basic conditions are not provided the child encounters a hurdle which persists through to adulthood. The talented sports stars who represent our nation do so because they have well-refined skills and have had the opportunity from a very early age to develop and sharpen their skills. The development of motor skills is sequential - if any layer of development is incomplete, the next layer will be affected. There are windows of opportunity in which skills are developed, and if these opportunities are bypassed, the chances of developing them at a later stage are limited. A recent study of the fitness of South African children has shown that children from poorer areas under-perform in tasks of physical performance compared with children from more affluent areas. ${ }^{1}$ The differences can be attributed to the smaller size of the children from poor areas as well as underdeveloped motor skills. In this particular study the differences skills were noticeable in grade 1.

The most important training ground for skill development occurs at school. Until such time as all the schools have similar facilities and opportunities to participate in physical activity, our children will always have a range of developed skills which will persist through to adulthood. Suffice to say, it is highly unlikely a talented child coming from a deprived background will ever be able to compete equally with a talented child who has had an opportunity to develop his or her talent fully. There are many studies which demonstrate this.

To excel in high-level sport it is essential to implement a longterm athlete development programme. ${ }^{2}$ This type of programme considers and caters for the unfolding need to develop skill. A wellconstructed long-term athlete development programme reduces the advantages that early maturation might have, ${ }^{3}$ and results in a much larger pool of talented adult players from which the national team can be selected. Surely it is time that the political decision-makers faced the facts and addressed the problem of lack of transformation on the sports field by focusing attention on schools and ensuring that facilities in the poor schools are upgraded to match the facilities in the schools from more affluent areas. Failure to do so will ensure that the situation we currently have will persist into the next generation. Shifting the attention and blame to the coach and sporting federation is a cheap shot which exposes their ignorance and lack of understanding of the principles of talent development. Sustainable changes are beyond the influence of the sporting federations, and remain firmly with the government, in particular the Departments of Education, Sport and Health. If the long-term athlete development model was understood and embraced by these departments, the concern of having national teams which do not represent the demographics of the general population will be a thing of the past.

This brings us to the contents of this edition of the journal. The concept of the long-term athlete development model is discussed with reference to rugby. The procedures adopted in South Africa are compared with the procedures of Australia and New Zealand. In addition the abstracts and posters presented at the 4th Clinical Sports Medicine Conference - Injury Prevention and Protection of the Health of the Athlete, 13 - 15 October 2010, Cape Town, are published in this edition. This edition also includes a paper which shows that the elite athletes drink much less than the recommendations suggest. Apart from making this finding this study also shows how important questions can be answered by substituting a large budget with a creative research plan. There is also a practical evidenced-based article on pre-participation screening for rugby players ('BokSmart: Pre-participation screening of rugby players by coaches based on internationally accepted medical standards'). This paper was one of the papers commissioned by BokSmart. More excellent practical papers on injury prevention, rehabilitation and training for rugby can be found at www.boksmart.com.

Finally, Dr Maaki Ramagole co-ordinated the development of the SASMA position statement on managing athletes with disorders of sexual development (DSD). This document will serve as a guideline for managing disorders of sexual development in future and will avoid a repetition of the unpleasant situation we experienced last year. There are many interesting articles in this edition - we hope you enjoy the read!

\section{Mike Lambert}

Editor-in-Chief

1. Armstrong ME. Youth fitness testing in South African primary school children: National normative data, fitness and fatness, and effects of socioeconomic status. PhD thesis, University of Cape Town, 2009.

2. Vaeyens R, Lenoir M, Williams AM, Philippaerts RM. Talent identification and development programmes in sport : current models and future directions. Sports Med 2008;38(9):703-714.

3. Malina RM, Brown EW. Growth and maturation of football players: implications for selection in youth programs. Insight 1998;2(1):27-30. 